\title{
Multivariate Characterization of Biological Efficiency in Dairy Cows in Grazing Systems
}

\author{
P. R. Marini ${ }^{1,2}$, R. Castro ${ }^{1}$, E. Frana ${ }^{1} \&$ R. J. Di Masso ${ }^{1,2}$ \\ ${ }^{1}$ Facultad de Ciencias Veterinarias, Universidad Nacional de Rosario, Ovidio Lagos y Ruta 33, Casilda (2170), \\ Santa Fe, Argentina \\ ${ }^{2}$ Carrera del Investigador Científico, Universidad Nacional de Rosario, Argentina \\ Correspondence: Marini, P. R., Facultad de Ciencias Veterinarias, Universidad Nacional de Rosario, Ovidio \\ Lagos y Ruta 33, Casilda (2170), Santa Fe, Argentina. E-mail: pmarini@fveter.unr.edu.ar
}

Received: June 27, 2017 Accepted: August 24, 2017 Online Published: September 14, 2017

doi:10.5539/sar.v6n4p83 URL: https://doi.org/10.5539/sar.v6n4p83

\begin{abstract}
Retrospective data was used corresponding to the lactation of 216 first and multi-pregnancy cows, American-Canadian Holstein with registers of their whole productive life, from their entrance to the system till their sale or death, registers were gathered from1992-2012 in the Argentinian Holstein farm located in Casilda, province of Santa -Argentina. During the mentioned time, all the cows were managed in the same dairy premises. The animals were divided into two categories: pure cows $(\mathrm{VP}, \mathrm{n}=88)$ and cows with breeding registers $(\mathrm{VRC}, \mathrm{n}=$ 128). The variables under use were: age at first calving, in days (EPP), first calving - conception interval in days (IPP), milk production adapted to 305 lactation days, in litres (PL), the amount of butyric fat produced, in kilograms (GB), the number of calvings registered throughout its reproductive life (NP), milk index in litres (IL) and the fat index in kilograms (IG). There were statistically significant differences as regards the productive characteristics PL and GB. N average, throughout the cycle under study, the VP produced 591 litres of milk and $161 \mathrm{~kg}$ of fat more. There were no significant differences when considering the age of first calving or the calving - conception interval. VP cows registered higher IL and IG than VRC cows, with significant differences which favoured the former, in both cases. The four components generated by the multivariate analysis explained important portions of the total variance which lead to consider all of them when interpreting the joint relations between productive performance indicators and reproductive achievement. It is concluded that even though the biotypes under study behave differently, both coincide at the point of stating that those cows which belong to quadrant IV were those which presented the best adaptation to the environment, being the ones who live longer and with an intermediate reproductive efficiency, regardless their biotype.
\end{abstract}

Keywords: multivariate analysis, reproductive performance, production, reproduction, biotype

\section{Introduction}

The efficiency of a productive system is one of the most important factors both from the economical point of view as well as from the social one. The most common way to evaluate it is by calculating the indexes of biological and economical productivity. However, when there is production with scarce and expensive resources, the efficiency should be evaluated not only through the products or outputs of the system but also in reference to the supplies. In the particular case of highly productive dairy cows, the characteristics associated to biological efficiency or fitness - reproduction and longevity - have been deteriorating despite their vital importance for the industry (Rauw et al., 1998). Dillon et al. (2006) states that sustainability of dairy systems widely depends on the availability of a biotype adapted to the handling conditions and able to efficiently transform food into good quality milk. Such biotype must- together with its productive performance - present a good reproductive performance, being the ultimate goal to maximize an efficient productive response for surface unit (González et al., 2005). This efficiency of production in dairy cows is closely related to the amount of milk produced in their successive lactations and to the number of lactations, that is to say to their longevity; reason why verifying an efficient performance indicates that cows indeed get pregnant, a point which at the same time shows their adaptation. Cows with a longer productive life have a higher accumulated production of milk and its components, have more calves and reduce the rate of rodeo reposition (Dutour \& Melucci, 2010; Camargo, 2012). It is when considering this approach that it is convenient to take advantage of pasturing systems where cows directly 
provide themselves the necessary supplies to satisfy their feeding needs, without the need of transportation, processing or distribution of rations (Molinuevo, 2005). Even though it is the most widely spread system, the litres of milk produced per cow do not represent the most apropriate indicator in order to make such a complex variable as productive efficiency operational, and therefore it should be complemented or replaced by other indicators which become alternatives of measuring production more comprehensively in order to value their behaviour in pasturing systems. Having indicators of this kind, when analysing a good dairy cow, would contribute to avoid overstimating one of the characteristics involved over other important ones, and would allow the identification of biotypes more adapted to the different environments at the premises of evaluation. The aim of this study was to evaluate the biological efficiency of dairy cows in pasturing systems, using a multivariate characterization which includes both productive as well as reproductive aspects.

\section{Materials and Methods}

Retrospective data was used corresponding to the lactation of 216 first and multi-pregnancy cows, American-Canadian Holstein with registers of their whole productive life, from their entrance to the system till their sale or death, registers were gathered between the years 1992 and 2012 in the Argentinian Holstein farm owned by the Agricultural School General San Martin located in Casilda, dependent on the National University of Rosario. This is located in Casilda, province of Santa Fe - Argentina ( $33^{\circ} 02^{\prime} 39^{\prime \prime}$ south latitude, 61 $10^{\circ} 05^{\prime \prime}$ west longitude). The premises have official milking control from the Rural Society of Totoras, Official Entity ${ }^{\circ}$ 13. During the period evaluated, all cows were handled within the same dairy facilities. The animals were divided into two categories: pure cows (VP, $n=88$ ) and cows with breeding register (VRC, $n=128$ ). The difference between them is that the former ones are always inseminated with semen from tested bulls, while such practice is not constantly maintained in the latter ones. In order to reach the condition of pure, they are required seven generations with tested bulls, which implies that the members of the group of cows with breeding records are at different stages of that way. Throughout the period under study the cows consumed grasses under direct pasturing (politific pastures and annual grasses of winter and summer) or conserved (silages of whole plant of maize and sorghum, meadow hay) and concentrated (maize and sorghum grains). During that time, the weather varied widely, both as regards rainfall as well as the temperature-relative humidity combination. Each cow belonging to the groups mentioned was characterized according to the values of two reproductive indicators: age at first calving, in days (EPP), and the interval first calving - calving in days (IPP) and two productive indicators: milk production adjusted to 305 days of lactancy, in litres (PL) and amount of butyric milk produced, in $\mathrm{kg}(\mathrm{GB})$. Despite the fact that the production of fat is related to the quantity of milk, both indicators were included because milk production does not refer to real values but to values adjusted to the length of lactancy common in every individual (305 days) while the amount of fat shows the kilograms of butyric fat really produced through all the productive life of the animal. The reason of including the reproductive variables EPP and IPP is that the former is related to the age at first calving and therefore to precocity and the latter to the impact it has on the reproductive efficiency. The effect each type of cow - pure or with breeding registers- has on the different variables was evaluated with a univariate analysis using the $t$ student test for independent data. With the aim of investigating certain possible assimilable grouping to potential groups with different contributions of the variables studied, a multivariate technique of main components was used (Carrasco \& Hernán, 1993). For statistical analysis, the main components corresponding to each animal -generated with the multivariate approach, were taken as new random variables. Individual values corresponding to the first main component (PC1) in combinations independent with (a) the second main component (PC2), (b) the third main component (PC3) and (c) the fourth main component (PC4), were graphed in several systems of orthogonal cartesian coordinates. In each of the three elements mentioned -PC1 versus PC2, PC1 versus PC3 and PC1 versus PC4- four quadrants were defined, correlatively numbered from I to IV, anticlockwise, starting with the top right quadrant. Next, the animals located in each quadrant were identified, which allowed us to define, for each combination of the components taken in pairs, four groups of cows. At the same time, the type of cow (pure and with breeding registers) was discriminated within the quadrant. The association between both categories (type of cow and corresponding quadrant) was evaluated, in each case, with a test $\mathrm{X}^{2}$ of independence. The effect of the corresponding quadrant on each one of the productive and reproductive variables involved in the calculations of the components, to which three indicators were added related to the longevity of the cows: (1) NP, number of calvings registered through its total reproductive life: (2) IL, milk index, defined as the milk daily production of the cows and calculated as the quotient between the total production of milk in litres achieved by a cow through its life and the number of days required for producing them and (3) IG, fat index, defined as the production of butyric fat per day of life of the cow and calculated as the quotient between the total production of butyric fat in kilograms achieved by a cow through its life and the number of days required to produce them; that was evaluated with a variance analysis to a classification criterion (quadrant) followed by the test of multiple comparisons of 
Bonferroni.

\section{Results}

\subsection{Univariate Analysis}

The average number of calvings was 4, being 1 the minimum and 9 the maximum for pure cows and 3 calvings minimum 1 , maximum 10 , for cows with breeding registers, a non statistically significant difference (test $\mathrm{U}$ de Mann-Whitney: $\mathrm{U}=5496 ; \mathrm{P}=0.760$ ).

Table 1 shows the values of productive and reproductive indicators registered on both groups.

Statistically significant differences were observed for the productive characters PL and GB. In average, throughout the cycle under study, pure cows produced 591 more litres of milk and $161 \mathrm{~kg}$ more of fat. Cows of both groups showed no significant differences as regards age at first calving (which tended to be higher in the non-pure ones: +17 days) nor as the interval calving-conception (which tended to be higher in the pure ones: +18 days. VP presented higher IL and IG than the VRC with significant differences which favoured the former ones, in both cases.

Table 1. Productive and reproductive indicators in two types of dairy cows in a grazing system

\begin{tabular}{lllll}
\hline & Pure cows & cows with breeding register & T & $P$ \\
\hline PL $(\mathrm{kg})$ & $6305 \pm 107$ & $5714 \pm 83$ & 4.415 & $<0.0001$ \\
\hline GB $(\mathrm{kg})$ & $882 \pm 45,8$ & $721 \pm 37.7$ & 2.714 & 0.007 \\
\hline EPP (días) & $963 \pm 18,7$ & $980 \pm 18.2$ & 0.515 & 0.652 \\
\hline IPP (días) & $495 \pm 9,7$ & $477 \pm 9.0$ & 1.336 & 0.0915 \\
\hline IL & $9,63 \pm 0,256$ & $8,17 \pm 0.232$ & 4.144 & $<0.0001$ \\
\hline IG & $0,330 \pm 0,0086$ & $0,277 \pm 0.0071$ & 4.772 & $<0.0001$ \\
\hline
\end{tabular}

Sample size - VP: $\mathrm{n}=88$; VRC: $\mathrm{n}=128$

All values correspond to the arithmetic average \pm standard error

\subsection{Multivariate Analysis}

The four components generated in the analysis explained important parts of the total variance which revealed the importance of considering all of them in the interpretation of the joint relations among the indicators of productive and reproductive performance.

The first component (PC1) explained $35.12 \%$ of the observed variance and correlated positively and significantly $(\mathrm{P}<0.0001)$ with milk production $(\mathrm{r}=0.804)$ and with fat production $(\mathrm{r}=0.544)$ and in a negatively and significantly way $(\mathrm{r}=-0.194 ; \mathrm{P}=0.004)$ with age at first calving and positively and significantly $(\mathrm{r}=0.652$; $\mathrm{P}<0.0001)$ with the interval calving - calving. The strongest association, judging from the coefficient of correlation, was observed with milk production adjusted to 305 days. Fat production and the interval calving calving presented similar coefficients and similar signs. Age at first calving showed low association with PC1 even though it reaches statistical significance mainly due to the high sample size. As a consequence, the first component was named "PRODUCTION". The higher PC1 value, the higher milk production and fat production. Those cows with higher production also show longer intervals between calvings and a tendency to be younger at first calving. Since pure cows have a higher milk production and a higher fat production, according to what the univariate analysis reveals (Table 1), these must have a higher value in that component [arithmetic average \pm standard error: Pure ones $=0.4065 \pm 0.1154$; With breeding registers $=-0.2793 \pm 0.1043 ; \mathrm{t}=4.338 ; \mathrm{P}<0.0001]$.

The second component (PC2) explained $25.04 \%$ of the variance and correlated positively and significantly $(\mathrm{r}=$ $0.865 ; \mathrm{P}<0.0001)$ with age at first calving and with the interval calving -calving $(\mathrm{r}=0.317 ; \mathrm{P}<0.0001)$ and in a negative and significant way $(\mathrm{r}=-0.313 ; \mathrm{P}<0.0001)$ with fat production; and positively and significantly with milk production $(\mathrm{r}=0.193 ; \mathrm{P}=0.005)$. The strongest association, judging from the value of the correlation coefficient observed, was observed in this case, as regards age at first calving. As a consequence the component was named "PRECOCITY". The higher the age at first calving component, the higher the calving-calving interval. Those animals which are sexually more precocious get pregnant earlier, give birth sooner and tend to have a shorter calving-calving interval even though the association to this last variable is not a strong one. Although the associations with both production variables are statistically significant their values are not high, especially in the case of milk production adjusted to 305 days. Anyway, tendencies suggest that the lower the PC2 value, the higher the fat production, being milk production a little lower. The univariate analysis indicates no statistically significant differences $(\mathrm{P}>0.05)$ between pure cows and those with breeding registers as regards 
age at first calving and calving-calving interval, that is why both categories of animals showed no differences in the value of the second component [arithmetic average \pm standard error: Pure $=-0.0207 \pm 0.0822$; with breeding registers $=0.0145 \pm 0.0959 ; \mathrm{t}=0.261 ; \mathrm{P}=0.796]$. Pure cows have a lower average value of the second component (PC2) in agreement with its little lower age at first calving (Table 1)

The third main component (PC3) explained $24.15 \%$ of the variance and was negatively and significantly correlated $(r=-0.436)$ with age at first calving and positively with the interval calving -calving $(r=0.540$; $\mathrm{P}<0.0001)$, it did not show an association $(\mathrm{r}=-0.075 ; \mathrm{P}=0.276)$ with milk production, however it did with fat production $(\mathrm{r}=-0.692 ; \mathrm{P}<0.0001)$. The strongest association, judging from the value of the correlation coefficient, was observed with fat production. The higher the value of the component, the lower the fat production, and vice-versa, independently from milk production adjusted to 305 days. That means a source of variation for fat not related to milk production. As a consequence the third component was named "FAT". The highest fat production corresponds to the lowest values of the component. These cows are older at first calving and have a shorter calving-calving interval. Both categories showed no differences in the value of the third component [arithmetic average \pm standard error: Pure $=-0.0969 \pm 0.1055$; with breeding registers $=0.0668 \pm$ $0.0866 ; \mathrm{t}=1.202 ; \mathrm{P}=0.231$ ]. The lowest value showed by pure cows is related to their higher fat production (Table 1)

Lastly, the fourth component (PC4) explained $15.7 \%$ of the variance and correlated positively and significantly ( $\mathrm{r}$ $=0.560 ; \mathrm{P}<0.0001)$ with milk production adjusted to 305 days, negatively and significantly $(\mathrm{r}=-0.340$; $\mathrm{P}<0.0001)$ with fat production, negatively and significantly $(\mathrm{r}=-0.435 ; \mathrm{P}<0.0001)$ with the interval calving-calving and showed no association $(\mathrm{r}=-0.095 ; \mathrm{P}=0.165)$ with age at first calving. Like in the first component, the strongest association, judging from the value of the coefficient of correlation, is observed in milk production adjusted to 305 days. At the same time, this component -like PC1, showed an association with the fat content, even though -unlike the observation of the first component, such association is -in this case, negative and with the interval between calvings and not with age at first calving ( $\mathrm{PC} 1$ shows a significant association with time at first calving but of a very low value, like in this case and in both the association is negative). As a consequence, the component was named "SKIMMEDLITRES" since: the higher the value of the component, the higher milk production adjusted to 305 days and the lower total fat production. These cows of higher production of skimmed milk - with higher values of PC4- show, at the same time, a shorter calving-calving interval, unlike cows with a higher milk production identified with the first component which present longer calving-calving interval. Both categories showed no differences in the value of the fourth component [arithmetic average \pm standard error: Pure $=0.0981 \pm 0.0917$; with breeding register $=-0.0675 \pm 0.0655 ; \mathrm{t}=1.510 ; \mathrm{P}=0.133]$.

Even though the analysis in main components did not show significant groupings, it revealed the existence of a population with an important variance in both kinds of cow.

When evaluating the whole behavior of the two first main components, it was verified that the distribution of the pure cows and the cows with breeding registers was non-homogeneous $\left(X^{2}=21.37 ; \mathrm{P}<0.0001\right)$ in the four quadrants. In the first quadrant there was a higher proportion of pure cows $(30 / 88=34.1 \%)$ than cows with breeding records $(23 / 128=18.0 \%)$, just like the fourth quadrant with $34.1 \%$ of the total pure cows $(30 / 88)$, facing $18.8 \%$ of cows with a breeding register (24/128). In the two remaining quadrants there were more cows with breeding registers, especially in the third quadrant with $35.9 \%(46 / 128)$ of them, versus $14.8 \%(13 / 88)$ of pure cows. In the second quadrant the values were $27.3 \%$ (35/128) versus $17.1 \%(15 / 88)$ respectively.

Table 2. Productive and reproductive indicators of pure cows divided in the quadrants they belong, based on the values of the two first main components

\begin{tabular}{llllllll}
\hline Cuadrante & NP & EPP & IL & IG & Pl305 & GB & IPP \\
\hline C I $(\mathrm{n}=30)$ & $3(1-8) \mathrm{b}$ & $1035 \pm 23 \mathrm{a}$ & $9.6 \pm 0.32 \mathrm{~b}$ & $0.319 \pm 0.01 \mathrm{~b}$ & $6858 \pm 141 \mathrm{a}$ & $858 \pm 74 \mathrm{~b}$ & $533 \pm 17 \mathrm{a}$ \\
\hline $\mathrm{C} \mathrm{II}(\mathrm{n}=15)$ & $3(2-6) \mathrm{ab}$ & $1134 \pm 44 \mathrm{a}$ & $7.8 \pm 0.39 \mathrm{c}$ & $0.261 \pm 0.01 \mathrm{c}$ & $5516 \pm 208 \mathrm{~b}$ & $651 \pm 60 \mathrm{c}$ & $458 \pm 18 \mathrm{~b}$ \\
\hline $\mathrm{C}$ III $(\mathrm{n}=13)$ & $3(1-6) \mathrm{b}$ & $850 \pm 36 \mathrm{~b}$ & $7.4 \pm 0.50 \mathrm{c}$ & $0.272 \pm 0.01 \mathrm{c}$ & $5059 \pm 173 \mathrm{~b}$ & $517 \pm 72 \mathrm{c}$ & $452 \pm 29 \mathrm{~b}$ \\
\hline $\mathrm{C} \mathrm{IV}(\mathrm{n}=30)$ & $4(2-9) \mathrm{a}$ & $853 \pm 22 \mathrm{~b}$ & $11.5 \pm 0.41 \mathrm{a}$ & $0.398 \pm 0.01 \mathrm{a}$ & $6686 \pm 121 \mathrm{a}$ & $1177 \pm 71 \mathrm{a}$ & $494 \pm 12 \mathrm{ab}$ \\
\hline
\end{tabular}

All values correspond to the arithmetic average \pm standard error except the NP (number of calvings) medium and range

a,b,c Valueswith different letter in the same column differ at least 0.05

Table 2 summarizes the values corresponding to pure cows. Productively speaking, those in the quadrant I and IV have higher production of both milk and fat and, at the same time, those in quadrant I had higher milk production and lower fat production than those in quadrant IV, seeing the signs of the bivariate correlations 
above mentioned. It was observed that cows in quadrant IV presented a higher average number of calvings, got pregnant earlier (younger at first calving), had an average calving-calving interval, presented higher values of IL and IG, but they were not the highest in production - since they were slightly overcome by those in quadrant I; and they did present the higher GB value.

Table 3 shows the values corresponding to cows with breeding registers. In this case, like in pure cows, those which presented the lowest values in milk production (quadrants II and III) also presented the shortest interval between calvings.

Table 3. Productive and reproductive indicators of cows with a breeding register divided in the quadrants they belong, based on the values of the two first main components

\begin{tabular}{cccccccc}
\hline Cuadrante & NP & EPP & IL & IG & Pl305 & GB & IPP \\
\hline C I $(\mathrm{n}=23)$ & $2(1-8) \mathrm{b}$ & $1058 \pm 31 \mathrm{~b}$ & $8.1 \pm 0.40 \mathrm{~b}$ & $0.280 \pm 0.01 \mathrm{~b}$ & $6729 \pm 151 \mathrm{a}$ & $682 \pm 72 \mathrm{~b}$ & $610 \pm 16 \mathrm{a}$ \\
\hline C II $(\mathrm{n}=35)$ & $3(1-7) \mathrm{a}$ & $1178 \pm 25 \mathrm{a}$ & $6.5 \pm 0.31 \mathrm{c}$ & $0.227 \pm 0.01 \mathrm{c}$ & $5281 \pm 122 \mathrm{~b}$ & $520 \pm 58 \mathrm{~b}$ & $452 \pm 13 \mathrm{~b}$ \\
\hline C III $(\mathrm{n}=46)$ & $4(1-7) \mathrm{c}$ & $853 \pm 21 \mathrm{c}$ & $7.8 \pm 0.29 \mathrm{c}$ & $0.264 \pm 0.01 \mathrm{~b}$ & $5247 \pm 105 \mathrm{~b}$ & $628 \pm 50 \mathrm{~b}$ & $430 \pm 11 \mathrm{~b}$ \\
\hline C IV $(\mathrm{n}=24)$ & $5(2-10) \mathrm{c}$ & $866 \pm 30 \mathrm{c}$ & $11.2 \pm 0.41 \mathrm{a}$ & $0.368 \pm 0.01 \mathrm{a}$ & $6265 \pm 147 \mathrm{a}$ & $1233 \pm 70 \mathrm{a}$ & $479 \pm 16 \mathrm{~b}$ \\
\hline
\end{tabular}

All values correspond to the arithmetic average \pm standard error except the NP (number of calvings) medium and range

a,b,c Values with different letter in the same column differ at least 0.05

The comparisons between the type of cows within the quadrant were not statistically significant except Il (> P), IPP $(<\mathrm{P})$ and IG $(>\mathrm{P})$ in quadrant I and Pl305 $(>\mathrm{P})$ in quadrant IV.

The evaluation of the joint behavior of first and third main components showed again a non-homogeneous distribution of both types of cows $\left(\mathrm{X}^{2}=22.67 ; \mathrm{P}<0.0001\right)$ in the four quadrants. In the first quadrant there was a higher proportion of pure cows $(25 / 88=28.4 \%)$ than cows with breeding registers $(26 / 128=20.3 \%)$, difference which became bigger in the fourth quadrant with a $39.8 \%$ of the total pure cows ( 35 / 88) versus $16.4 \%$ of cows with breeding registers (21/128). In the two remaining quadrants cows with breeding registers were predominant, particularly in the second quadrant with $39.1 \%$ of them (51/128) versus $19.3 \%(17 / 88)$ of pure cows. In the third quadrant the values were $24.2 \%$ (31/128) versus 12.5 (11/88) for cows with breeding registers and pure cows respectively.

Analyses within each group showed, in the case of pure cows (Table 4), that those in quadrant 4 had a higher number of calvings, got pregnant earlier (younger at first calving), had an average interval between calvings, presented higher average values of IL and IG, and even though it was not statistically significant - cows in quadrant I were those which produced the higher amount of GB.

Table 4. Productive and reproductive indicators of pure cows divided in the quadrants they belong, based on the values of the first and third main components

\begin{tabular}{cccccccc}
\hline Cuadrante & NP & EPP & IL & IG & Pl305 & GB & IPP \\
\hline C I $(\mathrm{n}=25)$ & $2(1-6) \mathrm{b}$ & $876 \pm 29 \mathrm{~b}$ & $9.4 \pm 0.42 \mathrm{~b}$ & $0.318 \pm 0.01 \mathrm{~b}$ & $6964 \pm 102 \mathrm{a}$ & $699 \pm 69 \mathrm{bc}$ & $561 \pm 17 \mathrm{a}$ \\
\hline C II $(\mathrm{n}=17)$ & $2(1-5) \mathrm{b}$ & $893 \pm 33 \mathrm{~b}$ & $7.1 \pm 0.39 \mathrm{c}$ & $0.255 \pm 0.01 \mathrm{c}$ & $5110 \pm 140 \mathrm{~b}$ & $455 \pm 79 \mathrm{bc}$ & $481 \pm 20 \mathrm{bc}$ \\
\hline C III $(\mathrm{n}=11)$ & $4(2-6) \mathrm{a}$ & $1171 \pm 41 \mathrm{a}$ & $8.4 \pm 0.60 \mathrm{bc}$ & $0.282 \pm 0.01 \mathrm{~b}$ & $5603 \pm 100 \mathrm{~b}$ & $797 \pm 98 \mathrm{~b}$ & $414 \pm 25 \mathrm{c}$ \\
\hline C IV $(\mathrm{n}=35)$ & $4(1-7) \mathrm{a}$ & $853 \pm 25 \mathrm{~b}$ & $11.4 \pm 0.30 \mathrm{a}$ & $0.398 \pm 0.01 \mathrm{a}$ & $6686 \pm 167 \mathrm{a}$ & $1177 \pm 59 \mathrm{a}$ & $494 \pm 15 \mathrm{~b}$ \\
\hline
\end{tabular}

All values correspond to the arithmetic average \pm standard error except the NP (number of calvings) medium and range

a,b,c Values with different letter in the same column differ at least 0.05

Table 5. Productive and reproductive indicators of cows with breeding registers divided in the quadrants they belong, based on the values of the first and third main components

\begin{tabular}{cccccccc}
\hline Cuadrante & NP & EPP & IL & IG & Pl305 & GB & IPP \\
\hline C I $(\mathrm{n}=26)$ & $2(1-5)$ c & $946 \pm 36 \mathrm{~b}$ & $8.3 \pm 0.40 \mathrm{~b}$ & $0.284 \pm 0.01 \mathrm{~b}$ & $6673 \pm 146 \mathrm{a}$ & $614 \pm 58 \mathrm{bc}$ & $617 \pm 14 \mathrm{a}$ \\
\hline C II $(\mathrm{n}=50)$ & $3(1-8) \mathrm{bc}$ & $902 \pm 25 \mathrm{~b}$ & $7.0 \pm 0.31 \mathrm{~b}$ & $0.237 \pm 0.01 \mathrm{c}$ & $5191 \pm 102 \mathrm{~b}$ & $472 \pm 41 \mathrm{c}$ & $450 \pm 10 \mathrm{~b}$ \\
\hline C III $(\mathrm{n}=31)$ & $4,5(1-7) \mathrm{b}$ & $1144 \pm 33 \mathrm{a}$ & $7.7 \pm 0.40 \mathrm{~b}$ & $0.266 \pm 0.01 \mathrm{~b}$ & $5382 \pm 133 \mathrm{~b}$ & $763 \pm 53 \mathrm{~b}$ & $419 \pm 13 \mathrm{~b}$ \\
\hline C IV $(\mathrm{n}=21)$ & $6(2-10) \mathrm{a}$ & $979 \pm 40 \mathrm{~b}$ & $11.4 \pm 0.41 \mathrm{a}$ & $0.372 \pm 0.01 \mathrm{a}$ & $6292 \pm 159 \mathrm{a}$ & $1367 \pm 64 \mathrm{a}$ & $456 \pm 16 \mathrm{~b}$ \\
\hline
\end{tabular}

All values correspond to the arithmetic average \pm standard error except the NP (number of calvings) medium and range 
As far as cows with breeding registers are concerned (Table 5) it was observed that those in Quadrant III were the ones who got pregnancy the latest and presented the shortest intervals between calvings, unlike the most productive group located in Quadrant I which presented the longest intervals between calvings, the lowest average number of calvings and -despite their high adjusted production of milk, they did not show the best indexes of milk or fat.

Comparisons between both types within the quadrant were not statistically significant, except for EPP (> RC), $\mathrm{NP}(>\mathrm{RC}), \mathrm{Pl} 305$ (>P), IPP (>P) and PL total (>RC) in Quadrant IV.

Lastly, Tables 6 and 7 summarize the values corresponding to pure cows and cows with breeding registers, respectively, in agreement with their location in the different quadrants defined when considering the values of the first and fourth components altogether.

Table 6. Productive and reproductive indicators of pure cows divided by the quadrant they belong to, based on the values of the first and fourth main components

\begin{tabular}{cccccccc}
\hline Cuadrante & NP & EPP & IL & IG & Pl305 & GB & IPP \\
\hline C I $(\mathrm{n}=32)$ & $3(1-6) \mathrm{b}$ & $943 \pm 30 \mathrm{a}$ & $10.5 \pm 0.3 \mathrm{a}$ & $0.354 \pm 0.01^{\mathrm{a}}$ & $7153 \pm 103 \mathrm{a}$ & $849 \pm 59 \mathrm{~b}$ & $480 \pm 13 \mathrm{~b}$ \\
\hline $\mathrm{C} \mathrm{II}(\mathrm{n}=13)$ & $2,5(2-6) \mathrm{b}$ & $970 \pm 50 \mathrm{a}$ & $7.7 \pm 0.6 \mathrm{~b}$ & $0.270 \pm 0.01 \mathrm{~b}$ & $5748 \pm 174 \mathrm{~b}$ & $515 \pm 100 \mathrm{c}$ & $408 \pm 22 \mathrm{c}$ \\
\hline $\mathrm{C} \mathrm{III}(\mathrm{n}=15)$ & $3(1-6) \mathrm{b}$ & $1027 \pm 43 \mathrm{a}$ & $7.6 \pm 0.5 \mathrm{~b}$ & $0.262 \pm 0.01 \mathrm{~b}$ & $4971 \pm 150 \mathrm{c}$ & $645 \pm 87 \mathrm{bc}$ & $491 \pm 19 \mathrm{~b}$ \\
\hline C IV $(\mathrm{n}=28)$ & $5(2-9) \mathrm{a}$ & $944 \pm 34 \mathrm{a}$ & $10.6 \pm 0.4 \mathrm{a}$ & $0.365 \pm 0.01^{\mathrm{a}}$ & $6274 \pm 118 \mathrm{~b}$ & $1238 \pm 68^{\mathrm{a}}$ & $557 \pm 15^{\mathrm{a}}$ \\
\hline
\end{tabular}

All values correspond to the arithmetic average \pm standard error except the NP (number of calvings) medium and range

a,b,c Values with different letter in the same column differ at least 0.05

Table 7. Productive and reproductive indicators of cows with breeding registers divided by the quadrant they belong to, based on the values of the first and fourth main components

\begin{tabular}{cccccccc}
\hline Cuadrante & NP & EPP & IL & IG & Pl305 & GB & IPP \\
\hline C I $(\mathrm{n}=20)$ & $3(1-6) \mathrm{b}$ & $922 \pm 42 \mathrm{a}$ & $9.2 \pm 0.49 \mathrm{a}$ & $0.313 \pm 0.01^{\mathrm{a}}$ & $6831 \pm 153 \mathrm{a}$ & $700 \pm 83 \mathrm{~b}$ & $512 \pm 20 \mathrm{ab}$ \\
\hline C II $(\mathrm{n}=39)$ & $3(1-8) \mathrm{b}$ & $980 \pm 33 \mathrm{a}$ & $7.4 \pm 0.32 \mathrm{~b}$ & $0.252 \pm 0.01 \mathrm{~b}$ & $5695 \pm 106 \mathrm{c}$ & $489 \pm 56 \mathrm{~b}$ & $406 \pm 13 \mathrm{c}$ \\
\hline C III $(\mathrm{n}=42)$ & $4(1-7) \mathrm{b}$ & $999 \pm 30 \mathrm{a}$ & $7.2 \pm 0.40 \mathrm{~b}$ & $0.243 \pm 0.01 \mathrm{~b}$ & $4851 \pm 109 \mathrm{~d}$ & $658 \pm 60 \mathrm{~b}$ & $470 \pm 14 \mathrm{~b}$ \\
\hline C IV $(\mathrm{n}=27)$ & $5(2-10) \mathrm{a}$ & $981 \pm 37 \mathrm{a}$ & $10.2 \pm 0.51 \mathrm{a}$ & $0.336 \pm 0.01^{\mathrm{a}}$ & $6307 \pm 135 \mathrm{~b}$ & $1161 \pm 73 \mathrm{a}$ & $572 \pm 18^{\mathrm{a}}$ \\
\hline
\end{tabular}

All values correspond to the arithmetic average \pm standard error except the NP (number of calvings) medium and range

a,b,c Values with different letter in the same column differ at least 0.05

Also in this case, the evaluation of the joint behavior of the two main components showed non-homogeneous distribution of the two types of cows $\left(\mathrm{X}^{2}=21.92 ; \mathrm{P}<0.0001\right)$ in the four quadrants.

The percentage of pure cows in the first quadrant $(32 / 88=36.14 \%)$ over doubled the corresponding to the cows with breeding registers $(20 / 128=15.6 \%)$, difference which persisted, smaller though, in the case of the fourth quadrant with a $31.8 \%$ of the total pure cows (28/88) versus $21.1 \%$ of cows with breeding registers (27/128). In the two remaining quadrants, the cows with breeding registers were majority. In the second quadrant there was $30.5 \%$ (39/128) of cows with breeding registers versus $14.8 \%(13 / 88)$ of pure cows. In the third quadrant the values were $32.8 \%(42 / 128)$ versus $17.1 \%$ (15/88) for cows with breeding registers and pure cows respectively. Comparisons between both types of cows within each quadrant were not statistically significant in any case. Once again, pure cows (Table 6) located in Quadrant IV were those which presented the higher number of calvings, with similar age at first birth and longer interval between calvings than those belonging to the other quadrants, and despite not being the most productive, they presented the highest levels of IL, IG and GB fat. The same behavior could be observed in the case of the cows with breeding registers. (Table 7)

\section{Discussion}

Worldwide, the production of dairy cows has widely increased in the last 40 years and, in some European countries, it has even doubled its levels. This change has been possible thanks to the combination of genetic improvements (artificial selection focused on individual production) as well as environmental ones (feeding and handling); all this guided by a particular approach which points out the volume of milk production as the main 
selective criterion (Rodríguez-Martínez et al., 2008). The farm evaluated in this work was not an exception in that sense. In the last 21 years analyzed, the group of the pure cows showed an increase of 4263 litres -from 3561 litres registered in 1992 to 7824 litres in the year 2012- which represents a steady growth of 203 litres per year (118\%) and an increase of 9.6 litres / cow / year which means a $5.6 \%$ annual growth, with significant differences year after year. On the other hand, the group of the cows with breeding registers showed, in the same 21 years, an increase of 3112 litres (year 1992: 3376 litres - year 2012: 6868 litres) which represent a growth of 148 annual litres (120\%) and 7 litres / cow / year (\%.7\%) with also significant differences year after year.

Worldwide, the genetic profit rate in milk production reaches $1.5 \%$ annually, thanks to the efficient use of artificial insemination (IA), to the progeny test and the intense selection of bulls for their use. This high productivity has come with a registered global decrease of reproductive efficiency of dairy rodeos, understanding by this the capacity of the cow to produce a living calf every year; a fact which is particularly observed in Holstein cows, predominant all over the world (Sørensen et al., 2007). This same pattern has been applied in Latin American countries, like Argentina, despite the dramatic differences between the systems of production in one environment and the other. As an example, it is worth mentioning that between the years 2001 and 2011, in Argentina, the use of national semen decreased $18 \%$ while the imported semen increased 135\%, reaching in 2011 a total of 2,123,587 sticks, which represented $82 \%$ of the market versus 467,854 sticks (18\% remaining) of national semen (Etcheverry 2012). This information lets us suggest that -through the migration of gametes, the genetic process verified in the males' origin land, was translated, in a major extent, to the rodeo of Holstein cows in Argentina; an idea which is generally shared by importers, sellers and advisors alike. The consequences of such a statement crash with the purposes declared in a more comprehensive vision of national milk production (Molinuevo 2005), which - considering that any production is a phenotypical complex expression, emphasizes the adjustment that there must be between the genetic potential of a productive specie and the particularities of the environment in which this specie must express such potential. The information gathered in this work permits the evaluation of two groups of cows which - starting from a univariate characterization and using the widely spread criterion of mil adjusted to 305 lactancy days (Searle \& Henderson, 1959), showed significant differences. Milk production in both groups match the information registered by Snyder (2006) and is lower than 7500 9000 litres cited in pasturing systems with local supplementation by Romano et al. (2016). The groups did not present significant differences as regards average age at first calving. The values obtained for this variable are higher than those informed by other authors (Pirlo et al., 2000; Salazar-Carranza et al., 2013) but coincide with Snyder et al. (2016) who informs average values for age at first calving of 31.3 months ( $94^{\circ}$ days) from information corresponding to 569,213 closed lactancies, which lasted over 90 days, during the period 1992-2012 of the National Milk Control organized and regulated by ACHA. Neither were there significant differences in the average values of the interval between calvings, being these higher than those informed by Krupic et al., (2015) and Snyder et al., (2016). It is clear that the reproductive inefficiency represents an obstacle for profit in milk exploitation and the sustainability of the system (Martins \& Pursley, 2016). On the other hand, although the increase in production has originated a decrease in the reproductive capacity, this one is not only associated to the litres of milk produced per lactancy, but it is also affected by other factors. About this, it is worth noticing that the reproductive efficiency of dairy cows decreased progressively for the last 50 years mainly due to the modification of two key matters: the problems for oestrus detection and the low efficiency of pregnancy reached by means of artificial insemination (Lucy, 2001; Washburn et al., 2002). When evaluating the milk (IL) and fat indexes (IG) as added indicators -as long as both of them consider productive and reproductive aspects simultaneously - significant differences were observed between both groups, with an average slightly superior performance of the pure cows and for both groups similar values to the ones informed by Marini et al. (2015). Considering these variables together would indicate that -in average- these cows do not present a high milk production, get to their first pregnancy quite late and show difficulties to get pregnant after their first calving, despite their interesting values of biological efficiency taking into consideration the values IL and IG.

Even though the consideration of each variable in isolation is relevant since it reveals reference values to rank these particular cows within the coherence of milk production for the Holstein race, the characterization of the efficiency of the productive system requires a joint analysis of all of them rather than their isolate consideration. Based on this premise, the information corresponding to the two indicators of productive performance and the two indicators of reproductive performance were analyzed by means of a multivariate technique of main components; and on these, other characters were added later, which permitted to enlarge the context of discussion.

On the basis that the components generated in the multivariate analysis may be considered as new random variables which -since they have no connection with each other- explain independent portions of the total 
variance observed in the population, it is worth highlighting two points: First is that all of them explain portions which are, despite being in decline from the first to the fourth, significant of the variation. The second is that the signs and correlations between values of each component and the productive and reproductive indicators which participate in the calculations reveal different associations which make it clear the complexity of the relations among those characters. As an example, the first component relates positively with fat and milk production, the second and the fourth components do it negatively with the first and positively with the second of these variables, with different intensities though; and the third component relates negatively with fat production and shows no significant relation with milk production.

The analysis considered only some of the possible combinations among the four components taking pairs and was restricted to those which included the first component since that was more closely related with milk production which has been the most interesting character when discussing about cow milk production. Undoubtedly, the highest proportion of pure cows in the right quadrants (I and IV) and the cows with breeding registers in the left ones (II and III) of the different combinations of values of the components, is because of the formers' higher production. However, within each quadrant, there were cows of both groups showing the variability of the population of pure cows which perform worse than cows with breeding registers. The joint consideration of the two first main components -productivity and precocity-; of the first and the third production and fat- and of the first and the fourth - production and skimmed litres- did not show a big difference in the predominance of pure cows or cows with breeding registers in each quadrant. The variable that makes a difference for this group of cows -independently from the fact that the former are pure or with breeding registersis their longevity evaluated from their number of calvings. In the last 25 years, the number of calvings per cow in races specialized in milk production has decreased from about 3.5 to approximately 3.0 (Knaus, 2009). Cows in the fourth quadrant presented average values between 4 and 5 lactancies in the case of the pure ones and between 5 and 6 lactancies in the case of those with breeding registers, with a little advantage on the latter in the three situations under consideration (Component 1 versus Component 2, versus Component 3 and versus Component 4). In evolutionary terms, longevity is correlated with a higher opportunity for reproduction and therefore, a higher biological efficiency. In productive terms, it is related to a lower reposition rate and a higher opportunity to cover such a reposition with cows from the same establishment, derived from a higher selection pressure.

At the same time, this longevity is associated with a production (6000- 6500 litres) in accordance to the nutritional and environmental specific conditions of pasturing systems in the warm region. Such productive level is achieved without affecting the reproductive efficiency, which translates to high IL and IG indicating adaptation to the system.

These cows -adapted to this particular system- present reproductive malfunctioning which is mainly due to the global handling as well as feeding one; but not to imbalance coming from a level of production incompatible with the particularities of the system they are in.

Despite the fact that the only selective criterion which had priority within this farm was milk production (Castro, personal communication), it could be observed that along the 21 years under analysis there coexisted different kinds of cows, pure ones as well as with breeding registers, with different productive strategies. Finally, the results show that the genetic variability within both groups of cows let them express their productive potential, in front of the existent limitations, with higher or lower impact on the reproductive aspects in a clear example of the correlation genotype-environment. It could be assumed that pasturing systems, by having lower levels of stress for the cows (Grandin, 2000), would permit a longer life although -many times- that is not possible due to the antagonism between production and reproduction (Frioni et al., 2016) associated to the limits of pasturing systems themselves, where the lack of control of many environmental factors (nutrition, handling and climate) plays a key role.

\section{Conclussion}

Even though in their univariate characterization as well as in their multivariate one, both types of Holsteins cows under study presented behaviours which are common, with particularities which -in the second type of analytical approach- appear in their distribution in the plans defined by the different combinations of the first component with the three remaining ones, coincidentally present that those cows located in Quadrant IV show a better adaptation to the pasturing system with supplementation, which is translated into a longer life - more time in the system - with productive levels compatible with the limitations of the system and with an intermediate reproductive efficiency, independently of their original biotype.

\section{References}

Camargo, O. (2012). Dairy cows between economic efficiency and biological inefficiency. Arch. Zootec. 61, 
13-29.

Carrasco, J. L., \& Hernán, M. A. (1993). Multivariate Statistics in the sciences of life. Ed. Ciencia 3, S.L. Madrid

Dillon, P., Berry, D., Evans, R., Buckley, F., \& Horan, B. (2006). Consequences of genetics selection for increased milk production in European seasonal pasture based systems of milk production. Livestock Science, 99, 141-158. https://doi.org/10.1016/j.livprodsci.2005.06.011

Dutour, E. J., \& Melucci, L. M. (2010). Association between productive and reproductive parameters of dairy cows according to their system of production. Latin American Association of Animal Production, 18(3-4), $133-147$

Etcheverry, J. (2012). Situation and evolution of the bovine genetic market in Argentina and the international market. Argentinian Chamber of Reproductive Biotechnology and Artificial insemination. CABIA 40 años. http//181.119.20.20/cabia/Etcheverry

Frioni, N., Urioste, J. I., Aguilar, I., \& Rovere, G. (2016). Genetic parameters of days open, milk, fat and protein yield of Uruguayan Holstein on pasture systems. Actas del XVI Congreso Latinoamericano de Genética. IV Congreso de la Sociedad Uruguaya de Genética. XLIX Reunión Anual de la Sociedad de Genética de Chile. XLV Congreso Argentino de Genética. 9 al 12 de octubre de 2016. Montevideo (República Oriental del Uruguay) pp190.

González, H., Magofke, J., \& Mella, C. (2005). Productivity, consume and biological efficiency in cows Frisón Neozelandés y F1 (Jersey-Frisón Neozelandés) delivered in late winter in Region X, Chile. Archivos medicina veterinaria, 37(1), 37-47.

Grandin, T. (2000). Principles of animal behaviour for the handling of bovines and other herbivorous in extensive conditions. Department of Animal Science - Colorado State University. Publicado en: Temple Grandin (comp.) Livestock Handling and Transport. CABI Publishing, Wallingford, Oxon (ReinoUnido), capítulo, 5, 63-85.

Knaus, W. (2009). Dairy cows trapped between performance demands and adaptability. J SciFood Agric, 89, 1107-1114. https://doi.org/10.1002/jsfa.3575

Krupic, M. L., Charmandarian, A. R., Pagni, C., \& Marini, P. R. (2015). Hip height measurements, production and reproduction in adult dairy cows in Argentina grazing systems. Asian Journal of Agriculture and Food Sciences, 3(2), 109-112.

Lucy, M. C. (2001). Reproductive loss in high-producing dairy cattle: where will it end? J Dairy Sci, 84, 1277-1293. https://doi.org/10.3168/jds.S0022-0302(01)70158-0

Marini, P. R., López, R. G., \& Di Masso, R. J. (2015). Short communication: U.S. dairy selection programs impact in Argentina. Cuban Journal of AgriculturalScience, 49(3), 299-305

Martins, J. P. N., \& Pursley, J. R. (2016). Fertility programs for lactating dairy cows, their physiological basis, and the factors that are critical for their success. Anim. Reprod., 13(3), 283-289. https://doi.org/10.21451/1984-3143-AR881

Molinuevo, H. A. (2005). Selection of dairy cows for the pasturing system. En: H. A .Molinuevo (Ed.) Genética bovina y producción en pastoreo. INTA, Argentina. 283-315.

Pirlo, G., Miglior, F., \& Speroni, M. (2000). Effect of age at first calving on production traits and on difference between milk yield returns and rearing costs on Italian holsteins. J. Dairy Sci., 83(3), 603-608. https://doi.org/10.3168/jds.S0022-0302(00)74919-8

Rauw, W. M., Kanis, E., Noordhuizen-Stassen, E. N., \& Grommers, F. J. (1998). Undesirable sideeffects of selection for high production efficiency in farm animals: a review. Livest Prod Sci, 56, 15-33. https://doi.org/10.1016/S0301-6226(98)00147-X

Rodriguez-Martinez, H., Hultgren, J., Båge, R., Bergqvist, A. S., Svensson, C., Bergsten, C., ... Gustafsson, H. (2008). Reproductive efficiency in dairy cows of high production: Is it sustainable with the current handling practices? .In: IVIS Reviews in Veterinary Medicine, I.V.I.S. (Ed.). International Veterinary Information Service, Ithaca NY (www.ivis.org).

Romano, G., Salas, M. S., \& Maiztegui, J. A. (2016). Effect of the season and the number of calving onthe total milk production 305 days of lanctancy,in Argentinian Holstein cows. XVII Jornadas de Divulgación Técnico-Científicas Facultad de Ciencias Veterinarias. IV Jornada Latinoamericana. II Jornadas de Ciencia 
y Tecnología 2016. Facultad de Ciencias Agrarias. I Reunión Transdisciplinaria en Ciencias Agropecuarias pp2.

Salazar-Carranza, M., Castillo-Badilla, G., Murillo-Herrera, J., \& Romero-Zúñiga, J. J. (2013). Age at first calving in Holsterin cows of dairy specialized in Costa Rica. Agronomía Mesoamericana, 24(2),233-243. https://doi.org/10.15517/am.v24i2.12522

Searle, S. R., \& Henderson, C. R. (1959). Establishing age-correction factors related to the level of herd production. J Dairy Sci., 42, 824-835. https://doi.org/10.3168/jds.S0022-0302(59)90659-9

Snyder, M. (2006). Cow raising in the farm business. Producir XXI, 14(176), 43-49.

Snyder, M., Andere, C., Rubio, N., Larsen, M., \& Casanova, D. (2016). Cow raising in Argentinian farms. AACREA. Association of Argentinian Holstein Breeders. Facultad de Ciencias Veterinarias - UNCPBA, 5.

Sørensen, A. C., Lawlor, T., \& Ruiz, F. A. (2007) Survey on fertility in the Holstein populations of the world. In: Proceedings of the IntConf on Fertility in dairy cows, Liverpool Hope University, UK, 30-31 August 2007 (EAAP Satellite Meeting), 1, 17.

Washburn, S. P., Silvia, W. J., Brown, C. H., McDaniel, B. T., \& McAllister, A. J. (2002). Trends in reproductive performance in Southeastern Holstein and Jersey DHIherds. J DairySci, 85, 244-251. https://doi.org/10.3168/jds.S0022-0302(02)74073-3

\section{Copyrights}

Copyright for this article is retained by the author(s), with first publication rights granted to the journal.

This is an open-access article distributed under the terms and conditions of the Creative Commons Attribution license (http://creativecommons.org/licenses/by/3.0/). 